\title{
The natural product lapiferin inhibits cell proliferation and promotes cell apoptosis in gingival squamous cell carcinoma via $\mathbf{P 2 1}$ regulation
}

\author{
LIN LIU $^{1}$, CHENG PENG ${ }^{1}$, YAN RUAN ${ }^{1}$ and QIAN ZHANG ${ }^{2}$ \\ ${ }^{1}$ Department of Stomatology, The Second Hospital of Tianjin Medical University, Tianjin 300211; \\ ${ }^{2}$ Department of Stomatology, School and Hospital of Stomatology, Tianjin Medical University, Tianjin 300070, P.R. China
}

Received January 24, 2018; Accepted May 29, 2019

DOI: $10.3892 / \mathrm{mmr} .2021 .12121$

\begin{abstract}
Gingival squamous cell carcinoma (GSCC) is responsible fora large proportion of oral cavity malignancies. GSCC is characterized by rapid cell growth, and progressive invasion and migration. P21 is a widely recognized tumor suppressor, which is induced by P53 activation; however, drugs that aim to promote $\mathrm{P} 21$-mediated tumor suppression remain to be identified. A natural compound library was used to perform broad-spectrum screening of drugs that could promote P21 expression. Subsequently, the effects of the screened drug on GSCC cell proliferation and apoptosis were evaluated. The results of the present study suggested that lapiferin was the most effective natural compound that promoted the expression of P21 at both mRNA and protein levels. Lapiferin inhibited proliferation and enhanced apoptosis of YD-38 GSCC cells in a dose-dependent manner. Furthermore, following treatment with lapiferin, the critical cell cycle regulators cell division cycle 25C and cyclin B1 and tumor cell proliferation markers proliferating cell nuclear antigen and Ki67 were markedly decreased. In addition, pro-apoptotic proteins were promoted following treatment of YD-38 cells with lapiferin. Following the depletion of $\mathrm{P} 21$ expression, lapiferin-mediated inhibition of cell proliferation and enhancement of cell apoptosis were significantly reduced. These results indicated that lapiferin may exert potent antitumor effects on GSCC via regulation of P21; therefore, lapiferin may be considered a potential, natural therapeutic agent for the treatment of GSCC.
\end{abstract}

\section{Introduction}

The majority of gingival tumors are highly differentiated squamous cell carcinomas, including gingival squamous cell

Correspondence to: Dr Cheng Peng, Department of Stomatology, The Second Hospital of Tianjin Medical University, 23 Pingjiang Road, Hexi, Tianjin 300211, P.R. China

E-mail: peng_cheng2017@sina.com

Key words: lapiferin, gingival carcinoma, proliferation, apoptosis, P21 carcinoma (GSCC) (1). GSCC occurs in either the maxilla or the mandible $(2,3)$. GSCC typically resembles a common periodontal lesion; therefore, the early presentation of GSCC is occasionally misdiagnosed as a benign inflammatory condition or oral allergy syndrome (4). In addition, GSCC is associated with a high risk of metastasis and bone invasion with delayed diagnosis $(5,6)$. In the early stages, GSCC is able to infiltrate into mandibular alveoli, leading to bone destruction, tooth mobility and pain (1). Chemotherapy is the main therapeutic strategy used to treat malignancies; for example, cisplatin, a DNA-damaging agent, has potent antitumor properties and is commonly used to treat various cancer types, including lung cancer (7), ovarian cancer (8), and head and neck carcinomas, particularly oral squamous cell carcinoma (9). Although cisplatin inhibits GSCC growth, it leads to severe adverse effects (10) and can lead to drug resistance (11). Therefore, more effective strategies with less toxic effects are required. As an alternative approach, malignancies may be more sensitive to antitumor agents obtained from natural products than traditional chemotherapy (12-15).

It has been $>20$ years since the identification of P21 as a P53-regulated cell-cycle inhibitor (16). The tumor suppressor P53 induces the expression of P21 to mediate $G_{1}$ arrest and cell apoptosis in tumors (17). P21 expression has been observed in tumors, and it has been widely recognized that P21 acts to restrain proliferation and tumor growth (18), and P21 is uniquely involved in maintaining $G_{1}$ cell-cycle arrest. Under unfavorable conditions, such as radiation, DNA-damaging

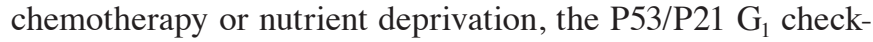
point is triggered and causes growth arrest until the damage is repaired or nutrients become available (18). However, it has been reported that $\mathrm{P} 21$ might have controversial roles, and it has been indicated that P21 may act as an anti-apoptotic agent (19).

Lapiferin is purified from the roots of Ferulalapidosa and has been identified as a complex ester of sesquiterpene alcohols. Although the configuration and structure of lapiferin has been revealed through chemical transformations and analysis of spectral characteristics (20), its role in gingival tumors remains to be elucidated.

In view of the antitumor potential of $\mathrm{P} 21$, the present study used P21-based screening of natural compounds to detect compounds that could promote the expression of P21 
and confer antitumor effects. All compounds from a commercially available compound library source were examined. The natural compounds that exhibited the highest capacity to promote $\mathrm{P} 21$ transcription were selected and subjected to further evaluation of antitumor properties. The present study identified lapiferin as a potent antitumor natural compound that exerted its effects via positively regulating P21 expression. To the best of our knowledge, this study is the first to identify an effective natural compound that targets GSCC, based on broad-spectrum drug screening.

\section{Materials and methods}

Cell culture. YD-38 human GSCC cells were purchased from the Cell Bank of Chinese Academy of Sciences (Shanghai, China), and were cultured according to the manufacturer's protocol. Cells were cultured in Dulbecco's modified Eagle's medium (DMEM; Gibco; Thermo Fisher Scientific, Inc.) supplemented with $10 \%$ fetal bovine serum (FBS; Gibco; Thermo Fisher Scientific, Inc.). The HGF-1 cell line (CRL-2014) was purchased from American Type Culture Collection (ATCC) and was also cultured in DMEM supplemented with $10 \%$ FBS. The culture media were replaced every 2 days, unless otherwise specified. Cells were incubated at $37^{\circ} \mathrm{C}$ in a humidified environment containing $5 \% \mathrm{CO}_{2}$.

Plasmid and small interfering (si)RNA transfection. The P21 luciferase reporter plasmid was constructed, according to the following procedures. The pGL3-basic vector (Promega Corporation) was digested using $K p n I$ and HindIII restriction enzymes. Primers (forward, 5'-GACTCTGTGATCAATTTC TT-3' and reverse, 5'-TTGTATCTCTGCAGGCG-3') were used to clone the P21 promoter from THLE-2 normal liver cells (ATCC), to which the KpnI and HindIII restriction enzymes were added (21). After PCR, double digestion and DNA gel (1\% agarose) extraction (22), the fragments were ligated together. Sequencing was used to ensure that the P21 luciferase reporter plasmid was successfully constructed. siRNAs were designed and synthesized by Shanghai GenePharma Co., Ltd. and were transfected into cells at a concentration of $10 \mu \mathrm{M}$. The sequences were as follows: siNC, sense 5'-ACUUAC GAGUGACAGUAGA-3', antisense 5'-UCUACUGUCACU CGUAAGU-3'; and siP21, sense 5'-CCAACUCAUUCUCCA AGUA-3' and antisense 5'-UACUUGGAGAAUGAGUUG G-3'. Briefly, YD-38 cells were seeded into 96-well plates at a density of 2,000 cells/well and transfection was performed using Lipofectamine ${ }^{\circledR} 3000$ (Invitrogen; Thermo Fisher Scientific, Inc.) according to the manufacturer's protocols. A total of $48 \mathrm{~h}$ post-transfection, subsequent experiments were conducted.

Luciferase reporter assay. Luciferase reporter assays were performed using the Dual-Luciferase ${ }^{\circledR}$ Reporter assay system (cat. no. E1910; Promega Corporation) according to the manufacturer's protocol. Briefly, YD-38 cells seeded into a 24-well plate at a density of 30,000 cells/well were transfected by Lipofectamine ${ }^{\circledR} 3000$ (Invitrogen; Thermo Fisher Scientific, Inc.) with P21 luciferase plasmid (1 $\mu \mathrm{g} / \mathrm{well})$ and Renilla vector (100 $\mathrm{ng} /$ well) and were treated with various natural products from the compound library at the Chinese
Academy of Sciences (working concentration, $10 \mathrm{mg} / \mathrm{ml}$ for each compound) for $24 \mathrm{~h}$ at $37^{\circ} \mathrm{C}$. Cells were then lysed with lysis buffer (Beyotime Institute of Biotechnology) for $20 \mathrm{~min}$ at room temperature with agitation $(150 \mathrm{rpm})$. Subsequently, the lysate was incubated with luciferase assay reagent II and the absorbance of all wavelengths was immediately analyzed. Finally, the Stop \& Glo reagent was added to the cells and absorbance was measured again (Tecan). Luciferase activities were determined by obtaining the ratio of the two readings; luciferase activity was normalized to Renilla luciferase activity.

Cell proliferation assay. YD-38 cells were seeded into 96-well plates (3,000 cells/well) and allowed to grow overnight. Cells transfected with siP21 $(10 \mu \mathrm{M})$ were subsequently treated with lapiferin $(10 \mu \mathrm{g} / \mathrm{ml})$, followed by incubation in DMEM for a further $72 \mathrm{~h}$. Cell proliferation was determined for 2 consecutive days using the MTT assay. Briefly, $2 \mathrm{mg} / \mathrm{ml}$ MTT solution was added to each well and the cells were incubated for $4 \mathrm{~h}$ at $37^{\circ} \mathrm{C}$. Subsequently, media were removed and $200 \mu \mathrm{l}$ dimethyl sulfoxide was added. The plate was agitated for $5 \mathrm{~min}$ and the optical density was subsequently determined at $490 \mathrm{~nm}$ using a spectrophotometer.

Reverse transcription-quantitative PCR (RT-qPCR). Total RNA was extracted from cultured GSCC cells using the RNA kit (Qiagen, Inc.) according to the manufacturer's protocol. Total RNA was reverse transcribed into cDNA using QuantiTect Reverse Transcription kit (Takara Bio, Inc.), according to the manufacturer's protocol. Primer sequences were as follow: p21, forward 5'-GAAAAGGAGAACACG GGATG-3', reverse 5'-AAAGTCACTAAGAATCATTTA TTG-3'; and $\beta$-actin, forward 5'-CGGAGTCAACGGATT TGGTC-3' and reverse 5'-AGCCTTCTCCATGGTCGTGA-3'. RT-qPCR was performed using a TaqMan miRNA RT-qPCR assay (Takara Bio, Inc.) equipped with ABI-PRISM 7300 system (Applied Biosystems; Thermo Fisher Scientific, Inc.). RT-qPCR thermocycling conditions were performed as follows: Denaturation at $95^{\circ} \mathrm{C}$ for $30 \mathrm{sec}$, followed by 45 cycles at $95^{\circ} \mathrm{C}$ for $3 \mathrm{sec}$ and $60^{\circ} \mathrm{C}$ for $30 \mathrm{sec}$. Expression was quantified using the $2^{-\Delta \Delta \mathrm{Cq}}$ method (23).

Cell apoptosis detection. The Annexin V/propidium iodide (PI) assay was performed according to the manufacturer's protocol (Invitrogen; Thermo Fisher Scientific, Inc.). Briefly, YD-38 cells $\left(1 \times 10^{5} /\right.$ well) were plated into 6 -well plates and treated with lapiferin $(10 \mu \mathrm{g} / \mathrm{ml})$ in the presence or absence of siP21 for $48 \mathrm{~h}$. Subsequently, cells were washed with pre-chilled PBS, trypsinized and resuspended in $100 \mu 1$ binding buffer containing $2.5 \mu$ l FITC-conjugated Annexin V and $1 \mu \mathrm{l} \mathrm{PI}(100 \mu \mathrm{g} / \mathrm{ml})$. Cells were then incubated at room temperature for $15 \mathrm{~min}$ in the dark. Finally, $\geq 10,000$ cells were collected and analyzed by flow cytometry (FACSCanto II; BD Biosciences) with FlowJo VX software (FlowJo, LLC). Cell apoptotic rates were assessed as follows: (Apoptotic cells in the control group-apoptotic cells in the lapiferin group)/apoptotic cells in the control group x 100 .

Western blot analysis. Total proteins were extracted from cultured YD-38 cells. Briefly, cells were grown until they 
reached 95\% confluence; after washing with PBS, cells were lysed using RIPA lysis buffer (Beyotime Institute of Biotechnology) to obtain the total protein lysate. Equal amounts of protein (30 $\mu \mathrm{g} / \mathrm{lane})$, the concentration of which was determined by the BCA method (Thermo Fisher Scientific, Inc.), were then subjected to 12 or $15 \%$ SDS-PAGE. Subsequently, the proteins were transferred to a PVDF membrane $(0.22 \mu \mathrm{m}$; EMD Millipore,) and blocked with 5\% milk dissolved in TBS-Tween $(0.1 \%)$ for $1 \mathrm{~h}$ at room temperature. GAPDH was detected as a loading control. Immunoreactivity was determined using enhanced chemiluminescence autoradiography (Thermo Fisher Scientific, Inc.). The membrane was incubated with primary antibodies overnight at $4^{\circ} \mathrm{C}$ and with secondary antibodies at room temperature for $1 \mathrm{~h}$. The following antibodies were used for western blotting: P21 (cat. no. ab109520; 1:1,000; Abcam), proliferating cell nuclear antigen (PCNA; cat. no. 10205-2-AP; 1:1,000; ProteinTech Group, Inc.), Ki67 (cat. no. ab15580; 1:1,000; Abcam), cell division cycle 25C (Cdc 25C; cat. no. ab32444; 1:1,000; Abcam), cyclin B1 (cat. no. ab72; 1:1,000; Abcam), cleaved (cl)-caspase-3 (cat. no. 9664; 1:1,000; Cell Signaling Technology, Inc.), cl-caspase-9 (cat. no. 20750; 1:1,000; Cell Signaling Technology, Inc.), Bax (cat. no. ab32503; 1:1,000; Abcam), cytochrome $c$ (cyto. C; cat. no. ab13575; 1:1,000; Abcam), cl-poly(ADP-ribose) polymerase (PARP; cat. no. ab32064; 1:1,000; Abcam), GAPDH (cat. no. sc-47724; 1:2,000; Santa Cruz Biotechnology, Inc.), and horseradish peroxidase-conjugated secondary antibodies (cat. nos. sc-2004 and sc-2005; 1:5,000; Santa Cruz Biotechnology, Inc.). Each experiment was repeated at least three times.

Statistical analysis. Data are expressed as the mean \pm standard deviation. One-way analysis of variance was used for comparisons among multiple groups ( $\geq 3$ groups), followed by a least significant difference post hoc test. $\mathrm{P}<0.05$ was considered to indicate a statistically significant difference. All experiments were repeated at least three times, unless otherwise stated.

\section{Results}

Lapiferin promotes $P 21$ luciferase activity in a human GSCC cell line. To identify natural products that target $\mathrm{P} 21$, natural compounds from the Chinese Academy of Sciences compound library, which consists of 480 natural products, were purchased. YD-38 cells were transfected with P21 luciferase plasmid and Renilla control plasmid for $24 \mathrm{~h}$ in 96 -well plates, after which the natural products were added to each well and mixed gently. As shown in Fig. 1, 30\% of the natural products inhibited the luciferase activities of P21 (green) and 53\% of the natural products promoted the luciferase activities of $\mathrm{P} 21$ in GSCC cells (red); the remaining compounds had no effect on P21 transcriptional activities. Of all the effective natural compounds, lapiferin increased P21 activity to the highest level compared with in untreated cells (6.32-fold). Therefore, this natural product was selected for subsequent analysis.

Lapiferin decreases cell proliferation in a dose-and time-dependent manner in GSCC. The present study examined the detailed effects of lapiferin on human GSCC cell proliferation. As shown in Fig. 2A, when YD-38 cells were

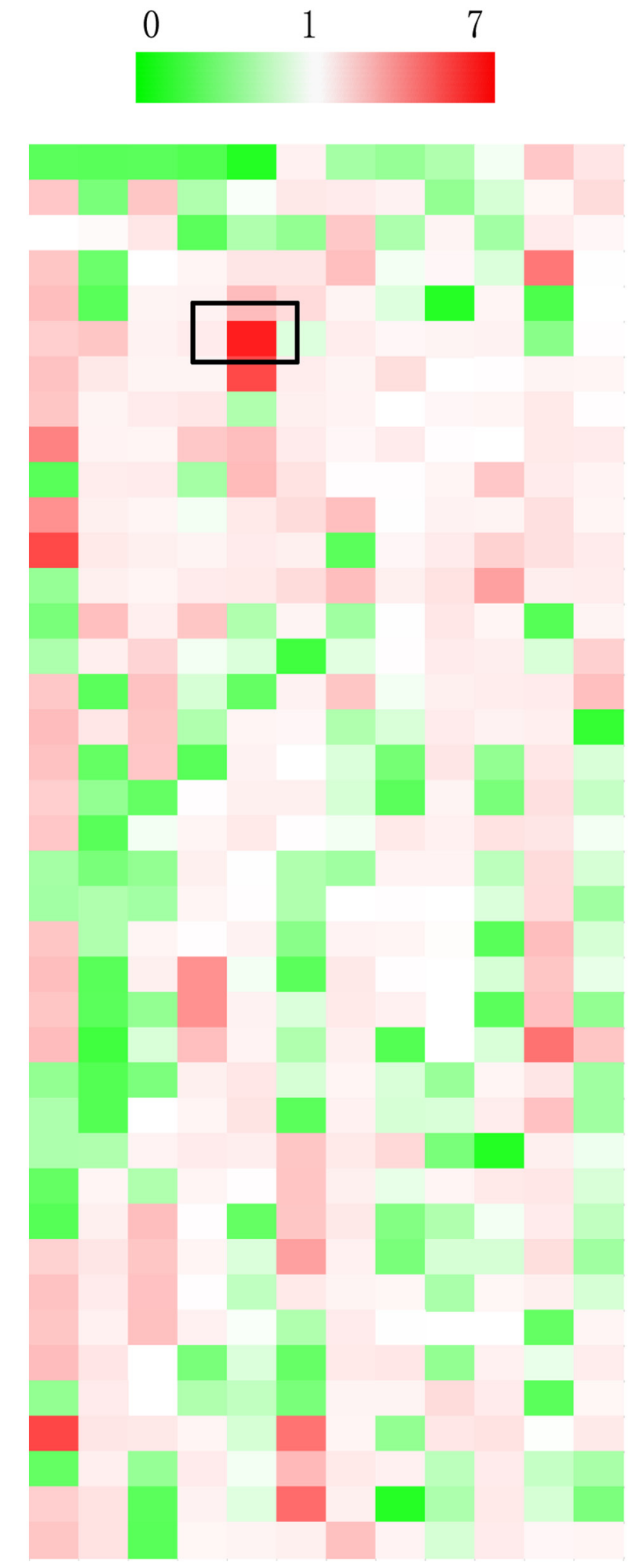

Figure 1. Lapiferin promotes P21 luciferase activity in the YD-38 human gingival squamous cell carcinoma cell line. Luciferase activities were detected to assess the effects of 480 natural products on the transcriptional activities of $\mathrm{P} 21$.

treated with lapiferin, the proliferative rates remained stable in response to a low dose of lapiferin $(2.5 \mu \mathrm{g} / \mathrm{ml})$, but gradually decreased as the concentration of lapiferin increased $(5,10$ and $20 \mu \mathrm{g} / \mathrm{ml}$ ). In addition, cell proliferation was determined at 
various time points. Similarly, cell proliferation was stable in response to lapiferin treatment for $12 \mathrm{~h}$; however, the cell proliferative rates were decreased to $75 \%$ when YD-38 cells were stimulated with lapiferin for $24 \mathrm{~h}$; the suppressive effects were further enhanced as the treatment time was extended (Fig. 2B). These findings suggested that lapiferin decreased cell proliferation in a dose- and time-dependent manner in human GSCC cells.

Lapiferin increases cell apoptosis in a dose- and timedependent manner in GSCC. Increased cell proliferation and decreased cell apoptosis are the two main manifestations of human malignancies. Therefore, the role of lapiferin in human GSCC cell apoptosis was determined. The results revealed that when cells were treated with lapiferin at a concentration of $5 \mu \mathrm{g} / \mathrm{ml}$, the cell apoptotic rates were significantly increased to 2.2-fold compared with in the control YD-38 group (Fig. 3A). Furthermore, cell apoptosis was assessed when cells were treated with lapiferin for various durations. As shown in Fig. 3B, the cell apoptotic rates remained stable at $12 \mathrm{~h}$ and were markedly increased when YD-38 cells were treated with lapiferin for increased durations. Cell apoptotic rates peaked (3.5-fold) when cells were treated with lapiferin for $48 \mathrm{~h}$. These results suggested that lapiferin increased cell apoptosis in a dose- and time-dependent manner in GSCC.

Lapiferin suppresses the protein expression of cell proliferation regulators in YD-38 cells. As shown in Fig. 1, lapiferin increased the luciferase activity of P21. The present study subsequently examined the effects of lapiferin by western blotting. GAPDH was included as an internal control. As shown in Fig. 4, when YD-38 cells were treated with lapiferin for $24 \mathrm{~h}$, the protein expression levels of P21 were markedly increased, which was consistent with the findings presented in Fig. 1. However, PCNA and Ki67, two cell proliferation markers, and $\mathrm{Cdc} 25 \mathrm{C}$ and Cyclin B1, key cell cycle regulators, were downregulated by lapiferin; these findings are concordant with those presented in Fig. 2. These data further suggested that treatment of cells with lapiferin decreased cell proliferation.

Lapiferin increases the protein expression levels of pro-apoptotic factors in YD-38 cells. The expression levels of cell apoptosis-related proteins were also examined by western blot analysis. As shown in Fig. 5, when the human GSCC cell line YD-38 was stimulated with lapiferin for $24 \mathrm{~h}$ at a concentration of $10 \mu \mathrm{g} / \mathrm{ml}$, the protein expression levels of cl-caspase-3, cl-caspase-9, Bax, cyto. C and cl-PARP were markedly increased; expression of the internal control GAPDH remained stable. These data indicated that lapiferin increased the expression of cell apoptosis-associated proteins in human GSCC.

Lapiferin decreases cell proliferation and increases cell apoptosis through regulating P21 in GSCC. Furthermore, the detailed mechanism underlying the role of lapiferin in human GSCC was explored. Firstly, the expression of P21 was knocked down in YD-38 cells using a specific siRNA against P21. As shown in Fig. 6A, the basal expression levels of P21 were low and treatment with lapiferin markedly increased P21;
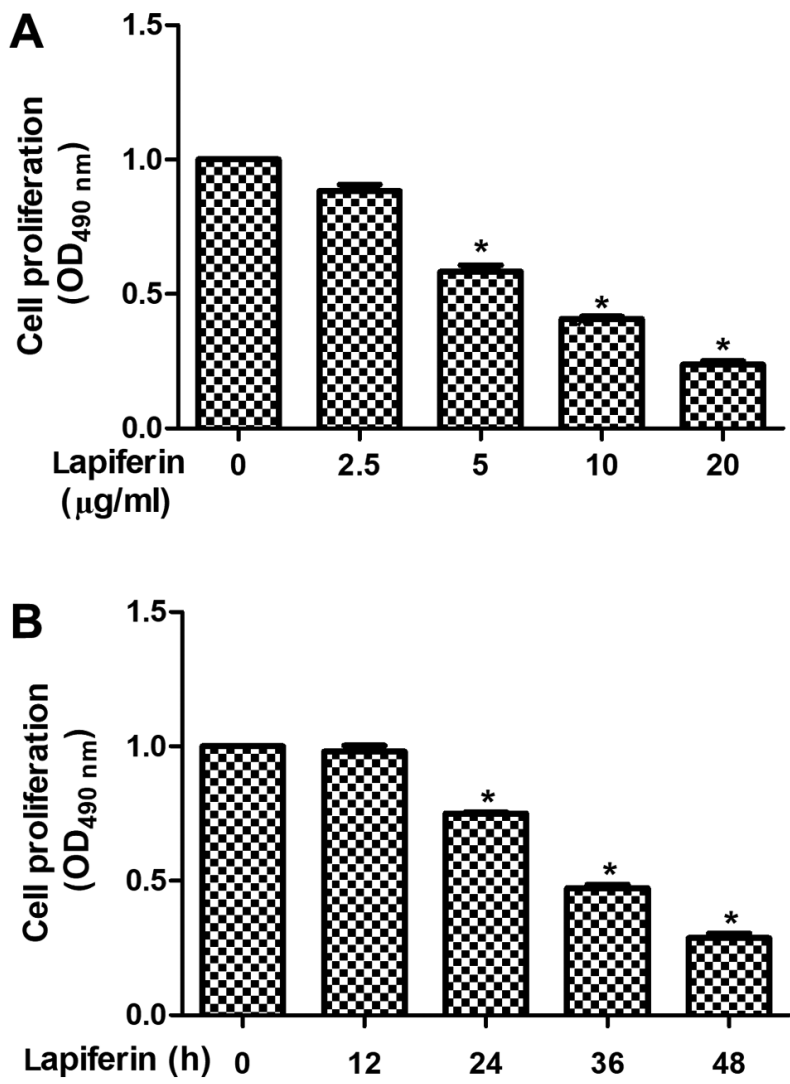

Figure 2. Lapiferin decreases cell proliferation in a dose- and time-dependent manner in GSCC. (A) YD-38 human GSCC cells were treated with increasing doses of lapiferin for $24 \mathrm{~h}$ and cell proliferative rates were assessed at a wavelength of $490 \mathrm{~nm}$. (B) YD-38 human GSCC cells were treated with lapiferin $(10 \mu \mathrm{g} / \mathrm{ml})$ for increasing durations and cell proliferative rates were assessed at a wavelength of $490 \mathrm{~nm}$. $\mathrm{P}<0.05$ vs. control. GSCC, gingival squamous cell carcinoma; OD, optical density.

however, when cells were transfected with siP21, the mRNA expression levels of P21 returned to basal levels. Accordingly, cell proliferation was decreased (Fig. 6B) and cell apoptosis was increased in response to treatment with lapiferin for $24 \mathrm{~h}$ (Fig. 6C). Notably, cell proliferation and apoptosis returned to a level comparable to the control when cells were transfected with siP21 (Fig. 6B and C). Taken together, these results suggested that lapiferin decreased cell proliferation and increased cell apoptosis through regulating P21 in human GSCC.

\section{Discussion}

Over $90 \%$ of cases of malignant neoplasms in the oral cavity are squamous cell carcinoma, the characteristics of which include rapid cell growth and progressive invasion and migration $(2,24)$. Squamous cell carcinoma is most commonly located in the lower lip, tongue and floor of the mouth, and GSCC accounts for $\sim 10 \%$ of cases of intraoral carcinoma (25).

Induction of P21 as a consequence of P53 activation has been widely recognized as exerting a tumor suppressive effect (18). P21 is currently accepted as a potent universal cyclin-dependent kinase (CDK) inhibitor (26), which physically interacts with, and inhibits, the activity of cyclin-CDK2, -CDK1 and-CDK4/6 complexes, thus functioning as a regulator 

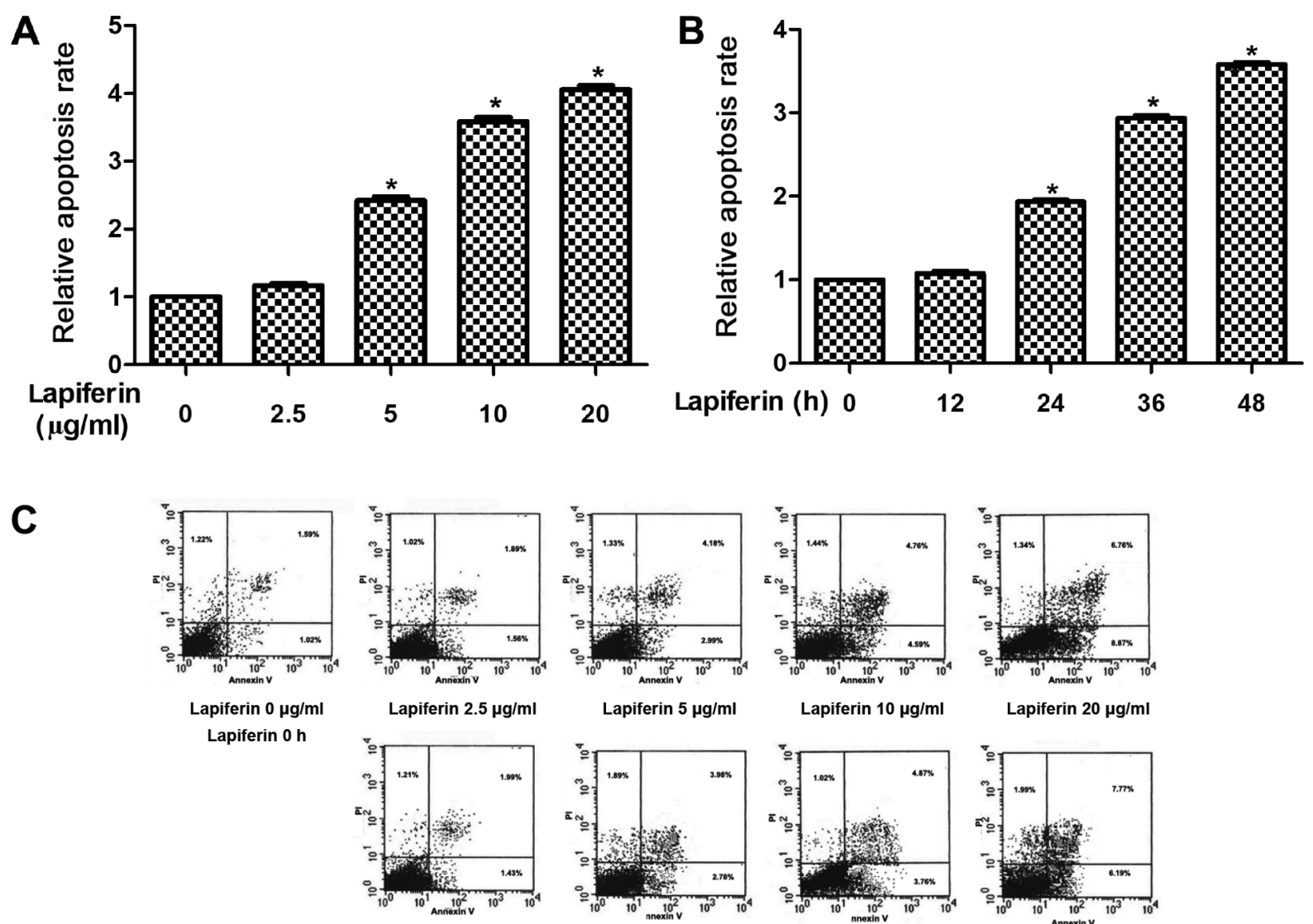

Lapiferin $5 \mu \mathrm{g} / \mathrm{ml}$

Lapiferin $10 \mu \mathrm{g} / \mathrm{ml}$
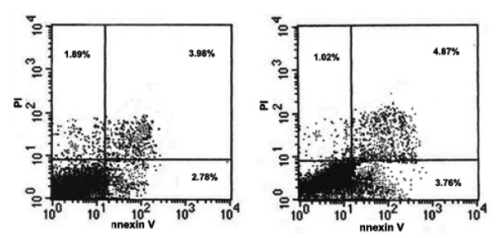

Lapiferin $36 \mathrm{~h}$

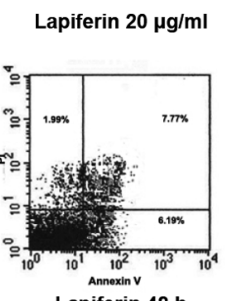

Lapiferin $12 \mathrm{~h}$

Lapiferin $24 \mathrm{~h}$

Lapiferin $48 \mathrm{~h}$

Figure 3. Lapiferin increases cell apoptosis in a dose- and time-dependent manner in GSCC. (A) YD-38 human GSCC cells were treated with increasing doses of lapiferin for $24 \mathrm{~h}$ and relative cell apoptotic rates normalized to the control group were assessed. (B) YD-38 human GSCC cells were treated with lapiferin $(10 \mu \mathrm{g} / \mathrm{ml})$ for increasing durations and relative cell apoptotic rates normalized to the control group were assessed. (C) Flow cytometry plots for cell apoptosis. ${ }^{*} \mathrm{P}<0.05$ vs. control. GSCC, gingival squamous cell carcinoma; OD, optical density.

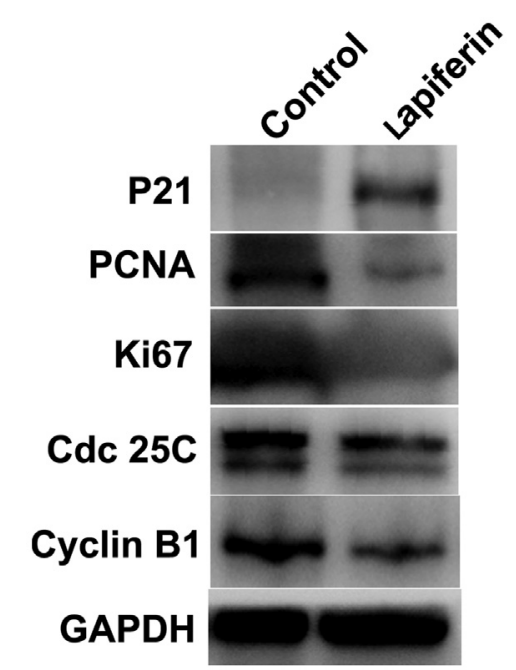

Figure 4. Lapiferin suppresses the protein expression levels of cell proliferation regulators in YD-38 cells. YD-38 cells were treated with lapiferin for $24 \mathrm{~h}$ at a dose of $10 \mu \mathrm{g} / \mathrm{ml}$, and the protein expression levels of P21, PCNA, Ki67, Cdc 25C, cyclinB1 and GAPDH were examined by western blot analysis. GAPDH was used as an internal control. Cdc 25C, cell division cycle 25C; PCNA, proliferating cell nuclear antigen.

of cell cycle progression during the $\mathrm{G}_{1}$ and $\mathrm{S}$ phases (27). Unraveling of the cell-cycle checkpoints, in particular the P53-dependent P21-requiring cell-cycle checkpoint after

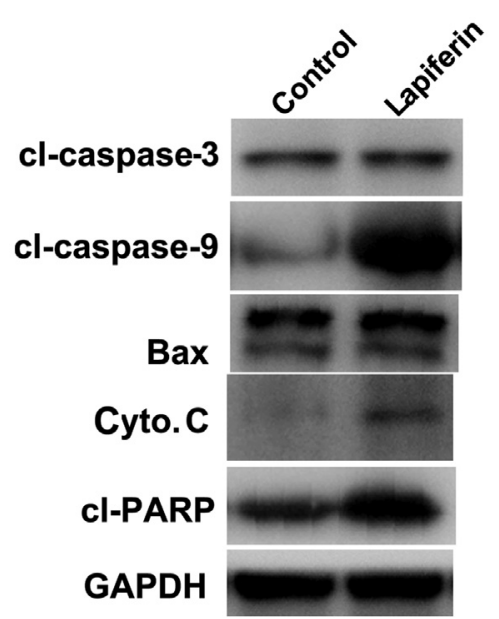

Figure 5. Lapiferin increases pro-apoptotic protein expression in YD-38 cells. YD-38 cells were treated with lapiferin for $24 \mathrm{~h}$ at a dose of $10 \mu \mathrm{g} / \mathrm{ml}$, and the protein expression levels of cl-caspase-3, cl-caspase-9, Bax, cyto. C, cl-PARP and GAPDH were examined by western blot analysis. GAPDH was used as an internal control. cl, cleaved; Cyto. C, cytochrome $c$; PARP, poly (ADP-ribose) polymerase.

DNA damage has provided a rationale for the development of tumor-specific therapeutic strategies (18).

The present study aimed to identify a potent natural compound that targetsP 21 based on the rationale that natural 

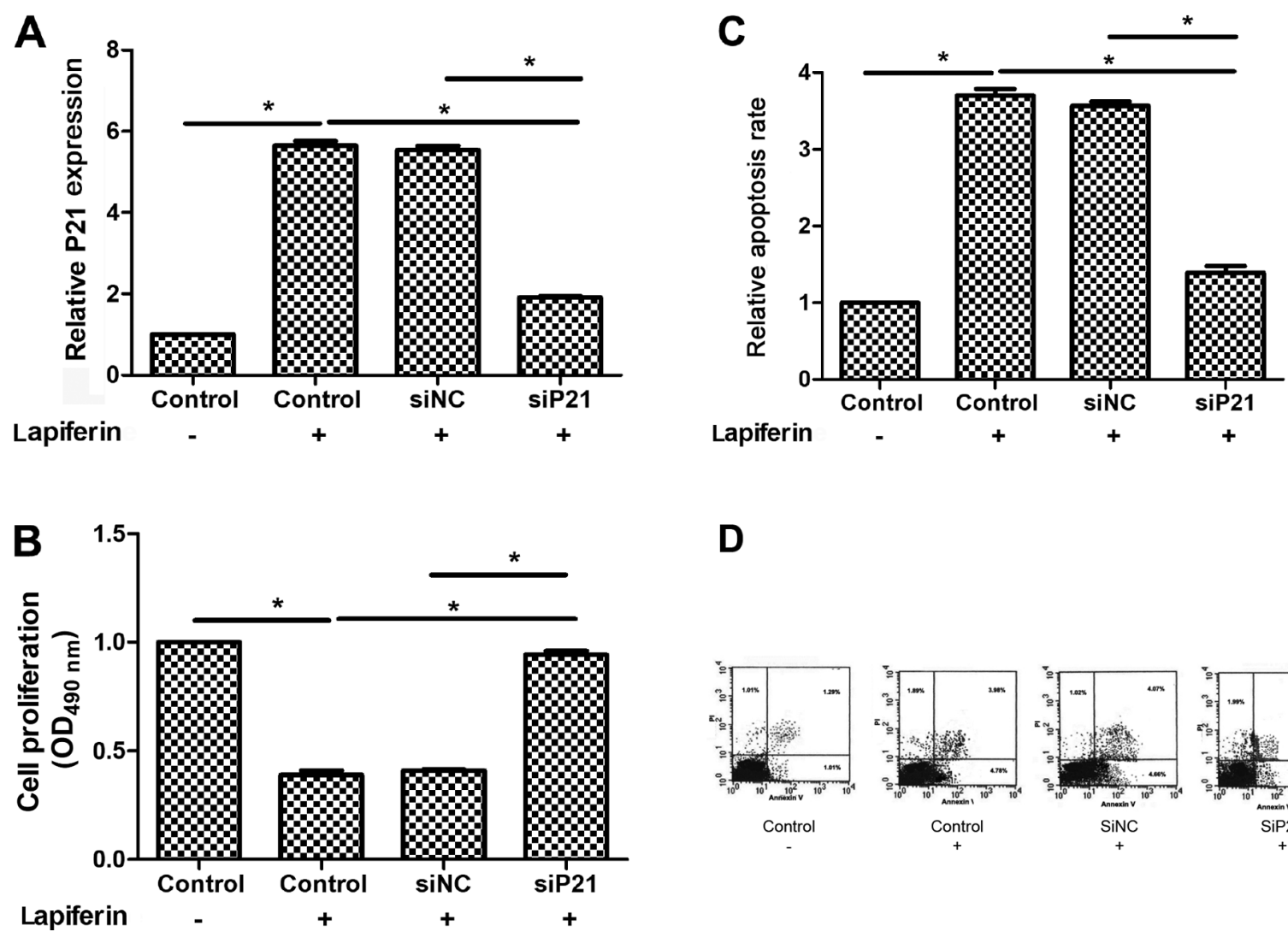

D
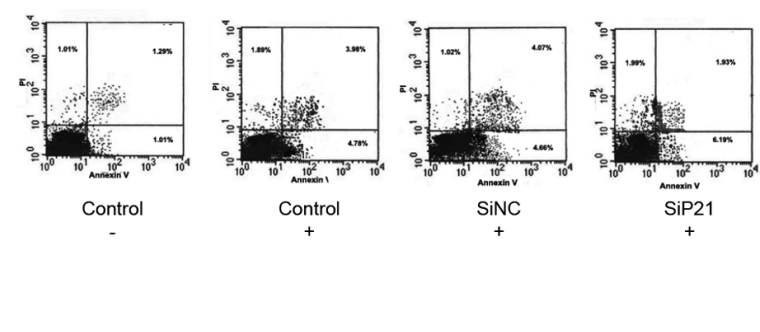

Figure 6. Lapiferin decreases cell proliferation and increases cell apoptosis through regulating P21 in human gingival squamous cell carcinoma. (A) P21 mRNA expression levels were detected using reverse transcription-quantitative PCR when YD-38 cells were transfected with or without siP21 in the presence or absence of lapiferin. (B) Cell proliferation was detected when YD-38 cells were transfected with or without siP21 in the presence or absence of lapiferin. (C) Relative cell apoptosis normalized to the control group was detected when YD-38 cells were transfected with or without siP21 in the presence or absence of lapiferin. (D) Flow cytometry plots for cell apoptosis. * $\mathrm{P}<0.05$, as indicated. NC, negative control; OD, optical density; si, small interfering RNA.

compound-activated P21 expression may confer antitumor potential. Using a compound library, it was demonstrated that lapiferin was one of the most effective natural compounds that promoted the expression of $\mathrm{P} 21$ at both transcriptional and protein levels. Lapiferin is a complex ester of sesquiterpene alcohols with aliphatic acid, which does not possess ionophoric properties (28). Earlier studies have purified lapiferin from the roots of F. lapidosa, and established its structure and configuration based on chemical transformations and analysis of spectral characteristics $(29,30)$. In addition, lapiferin extracted from $F$. communis and $F$. arrigoniisardinian has been shown to exert anti-proliferative activity against human colon cancer via interactions with type II estrogen-binding sites (20). Similarly, it has been reported that lapiferin derived from $F$. vesceritensis induces the apoptosis pathway in MCF-7 breast cancer cells (30). With the aid of compound library-based drug screening, this study revealed that lapiferin potently promoted P21expression. The proliferation of YD-38 GSCC cells was inhibited in response to lapiferin in a dose-dependent manner. Furthermore, the apoptosis of YD-38 GSCC cells was promoted by lapiferin treatment in a dose-dependent manner. Conversely, following knockdown of P21, lapiferin-mediated suppression of proliferation was markedly inhibited, indicating the P21-dependent mechanism of lapiferin-mediated antitumor activity. Previous reports $(20,30)$, together with the current study, indicated that lapiferin may confer potent antitumor effects on solid tumors.
Understanding the mechanism underlying the effects ofP53/P21 on tumor suppression has important implications for patients and cancer therapy (18). This study provided evidence to suggest that lapiferin may serve as a potential anti-proliferative natural compound against GSCC. Similar to previous reports $(20,30)$, this study revealed that lapiferin may regulate tumor cell apoptosis and proliferation; however, whether lapiferin has further functional roles in GSCC, including on cell migration and invasion, remains to be elucidated. Since GSCC has a high propensity to invade into adjacent tissues (31), the roles of lapiferin in GSCC cell metastasis warrant further investigation, and whether lapiferin-mediated protection from cell metastasis relies on P21 activation remains to be elucidated.

In conclusion, the present study used a multi-drug screening approach to identify lapiferin as a critical mediator of P21 activation that may lead to suppression of cell proliferation and induction of cell apoptosis in GSCC. To the best of our knowledge, this study is the first to systemically investigate the roles of lapiferin in GSCC. The findings indicated that lapiferin may serve as a potent anti-proliferative agent against GSCC and may have critical clinical implications.

\section{Acknowledgements}

The authors would like to thank Dr David White (Johns Hopkins University) for revising this manuscript. 


\section{Funding}

No funding was received.

\section{Availability of data and materials}

The datasets used and/or analyzed during the current study are available from the corresponding author on reasonable request.

\section{Authors' contributions}

LL performed most of the experiments. CP designed the project and analyzed the data. YR and QZ revised the manuscript and conducted some experiments. All authors read and approved the final manuscript.

\section{Ethics approval and consent to participate}

Not applicable.

\section{Patient consent for publication}

Not applicable.

\section{Competing interests}

The authors declare that they have no competing interests.

\section{References}

1. Gong Y, Yang $\mathrm{H}$ and Tian X: Elucidating the mechanism of miRNA-214 in the regulation of gingival carcinoma. Exp Ther Med 13: 2544-2550, 2017.

2. Keshava A, Gugwad S, Baad R and Patel R: Gingival squamous cell carcinoma mimicking as a desquamative lesion. J Indian Soc Periodontol 20: 75-78, 2016.

3. Okura M, Yanamoto S, Umeda M, Otsuru M, Ota Y, Kurita H, Kamata T, Kirita T, Yamakawa N, Yamashita T, et al: Prognostic and staging implications of mandibular canal invasion in lower gingival squamous cell carcinoma. Cancer Med 5: 3378-3385 2016.

4. Hinchy NV, Jayaprakash V, Rigual N, Reid M, Frustino JL, Rossitto R, Groman A and Sullivan MA: Progression of gingival squamous cell carcinoma from early to late stage after invasive dental procedure. Gen Dent 64: 38-43, 2016.

5. Fitzpatrick SG, Neuman AN, Cohen DM and Bhattacharyya I: Papillary variant of squamous cell carcinoma arising on the gingiva: 61 cases reported from within a larger series of gingival squamous cell carcinoma. Head Neck Pathol 7: 320-326, 2013.

6. Choi EJ, Zhang X, Kim HJ, Nam W and Cha IH: Prognosis of gingival squamous cell carcinoma diagnosed after invasive procedures. Asian Pac J Cancer Prev 12: 2649-2652, 2011.

7. Zhang F, Duan S, Tsai Y, Keng PC, Chen Y, Lee SO and Chen Y: Cisplatin treatment increases stemness through upregulation of hypoxia-inducible factors by interleukin- 6 in non-small cell lung cancer. Cancer Sci 107: 746-754, 2016.

8. Gao Y, Shan N, Zhao C, Wang Y, Xu F, Li J, Yu X, Gao L and Yi Z: LY2109761 enhances cisplatin antitumor activity in ovarian cancer cells. Int J Clin Exp Pathol 8: 4923-4932, 2015.

9. Florea AM and Büsselberg D: Cisplatin as an anti-tumor drug: Cellular mechanisms of activity, drug resistance and induced side effects. Cancers (Basel) 3: 1351-1371, 2011.

10. Huang $\mathrm{C}$ and $\mathrm{Yu} \mathrm{Y}$ : Synergistic cytotoxicity of $\beta$-elemene and cisplatin in gingival squamous cell carcinoma by inhibition of STAT3 signaling pathway. Med Sci Monit 23: 1507-1513, 2017.
11. Yang X, Tang C, Luo H, Wang H and Zhou X: Shp2 confers cisplatin resistance in small cell lung cancer via an AKT-mediated increase in CA916798. Oncotarget 8: 23664-23674, 2017.

12. Zhu X, Jiang H, Li J, Xu J and Fei Z: Anticancer effects of paris saponins by apoptosis and PI3K/AKT pathway in gefitinib-resistant non-small cell lung cancer. Med Sci Monit 22: 1435-1441, 2016.

13. Zhao PJ, Song SC, Du LW, Zhou GH, Ma SL, Li JH, Feng JG, Zhu XH and Jiang H: Paris Saponins enhance radiosensitivity in a gefitinib-resistant lung adenocarcinoma cell line by inducing apoptosis and G2/M cell cycle phase arrest. Mol Med Rep 13: 2878-2884, 2016.

14. Song S, Du L, Jiang H, Zhu X, Li J and Xu J: Paris saponin I sensitizes gastric cancer cell lines to cisplatin via cell cycle arrest and apoptosis. Med Sci Monit 22: 3798-3803, 2016.

15. Jiang H, Zhao PJ, Su D, Feng J and Ma SL: Paris saponin I induces apoptosis via increasing the $\mathrm{Bax} / \mathrm{Bcl}-2$ ratio and caspase-3 expression in gefitinib-resistant non-small cell lung cancer in vitro and in vivo. Mol Med Rep 9: 2265-2272, 2014.

16. el-Deiry WS, Tokino T, Velculescu VE, Levy DB, Parsons R, Trent JM, Lin D, Mercer WE, Kinzler KW and Vogelstein B: WAF1, a potential mediator of p53 tumor suppression. Cell 75: 817-825, 1993.

17. el-Deiry WS, Harper JW, O'Connor PM, Velculescu VE, Canman CE, Jackman J, Pietenpol JA, Burrell M, Hill DE, Wang Y, et al: WAF1/CIP1 is induced in p53-mediated G1 arrest and apoptosis. Cancer Res 54: 1169-1174, 1994.

18. El-Deiry WS: p21(WAF1) mediates cell-cycle inhibition, relevant to cancer suppression and therapy. Cancer Res 76: 5189-5191, 2016.

19. Georgakilas AG, Martin OA and Bonner WM: p21: A two-faced genome guardian. Trends Mol Med 23: 310-319, 2017.

20. Poli F, Appendino G, Sacchetti G, Ballero M, Maggiano N and Ranelletti FO: Antiproliferative effects of daucane esters from Ferula communis and $F$. arrigonii on human colon cancer cell lines. Phytother Res 19: 152-157, 2005.

21. Abbasi-Kenarsari H, Shafaghat F, Baradaran B, Movassaghpour AA, Shanehbandi D and Kazemi T: Cloning and expression of CD19, a human B-cell marker in NIH-3T3 cell line. Avicenna J Med Biotechnol 7: 39-44, 2015.

22. Zhang L, Lin J, Ma Y, Wei D and Sun M: Construction of a novel shuttle vector for use in Gluconobacter oxydans. Mol Biotechnol 46: 227-233, 2010.

23. Livak KJ and Schmittgen TD: Analysis of relative gene expression data using real-time quantitative PCR and the 2(-Delta Delta C(T)) method. Methods 25: 402-408, 2001.

24. Hoffman HT, Karnell LH, Funk GF, Robinson RA and Menck HR: The national cancer data base report on cancer of the head and neck. Arch Otolaryngol Head Neck Surg 124: 951-962, 1998.

25. Yoon TY, Bhattacharyya I, Katz J, Towle HJ and Islam MN: Squamous cell carcinoma of the gingiva presenting as localized periodontal disease. Quintessence Int 38: 97-102, 2007.

26. Xiong Y, Hannon GJ, Zhang H, Casso D, Kobayashi R and Beach D: p21 is a universal inhibitor of cyclin kinases. Nature 366: 701-704, 1993.

27. Gartel AL and Radhakrishnan SK: Lost in transcription: p21 repression, mechanisms, and consequences. Cancer Res 65: 3980-3985, 2005

28. Abramov AY, Zamaraeva MV, Hagelgans AI, Azimov RR and Krasilnikov OV: Influence of plant terpenoids on the permeability of mitochondria and lipid bilayers. Biochim Biophys Acta 1512: 98-110, 2001.

29. Golovina LA, Saidkhodzhaev AI, Abdullaev ND, Malikov VM and Yagudaev MR: Structure and stereochemistry of lapiferin. Chem Nat Compd 19: 281-285, 1983.

30. Gamal-EldeenAM and Hegazy ME: A crystal lapiferin derived from Ferula vesceritensis induces apoptosis pathway in MCF-7 breast cancer cells. Nat Prod Res 24: 246-257, 2010.

31. Kademani D: Oral cancer. Mayo Clin Proc 82: 878-887, 2007.

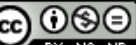

This work is licensed under a Creative Commons Attribution-NonCommercial-NoDerivatives 4.0 International (CC BY-NC-ND 4.0) License. 